\title{
Chapter XI \\ Online Participatory Decision Support Tools for Knowledge-Based Urban Development
}

\author{
Tan Yigitcanlar \\ Queensland University of Technology, Australia \\ Omur Saygin \\ Izmir Institute of Technology, Turkey \\ Jung Hoon Han \\ University of Queensland, Australia
}

\begin{abstract}
Particularly in the last decade, there have been a number of efforts to develop and then integrate planning support systems into existing geographic information systems. This integration brought a new technology called WebGIS, which enables geographic information systems functionalities through the Internet for decision support. No doubt there is a growing demand as more and more individuals want to use online government services to express their views and most importantly to take part in decisionmaking processes interactively. At this point, WebGIS offers a challenging opportunity for online participatory planning since the public could easily access alternative plans and the existing information in geographic information systems databases. This technology enables individuals to be able to take part in plan-making processes and contribute. This chapter explores how these new technological advances could achieve truly transparent plan-making process based on online participatory planning support tools that knowledge-based urban development could benefit from.
\end{abstract}




\section{INTRODUCTION}

The technological advances and social and economic changes that are characteristic of the late $20^{\text {th }}$ and $21^{\text {st }}$ century urban centers have created the need for new strategies of urban planning, such as knowledge-based urban development (KBUD) (Yigitcanlar, 2005a, 2007). The rapid development of advanced information and telecommunications networks has created new kinds of socio-economic activities. The changes in value systems and increases in cultural diversity within the cities have manifested the need for planning schemes based on flexibility and responsiveness to change. In contrast to motorization that completely altered the urban scene, information technology has quietly merged into the existing urban structure, causing little change in appearance. Nevertheless, the exponential growth of the Internet and related technologies and the increase in the utilization of computers have had profound effects on urban activities such as e-government, delivering services, goods, and so on. Although, a significant part of the citizens are still using government services in a traditional way, there is a strong tendency of using e-government services while more of these services are becoming available online in developed economies. The final report of the project funded by the European Community under the Information Society Technology Program (1998-2002) confirms this argument (see Figure 1).

The social life of cities has been changing. A diversity of lifestyles has been introduced to the cities which creates a need for more flexible planning schemes. The social challenges planners facing today address the problems of multi-cultural nature of modern cities as well as the problems caused by spatial distortions resulting from the development of new transportation and information networks. In the knowledge era, digital technology is rapidly deployed throughout urban space, and this technology becomes more important for urban life. In fact, social problems start to rise when a portion of the population cannot gain access to this technology (Shiode, 2000).

The rapid technologic and scientific changes have altered the nature of urban planning dramatically. In the last three decades, a number of computerized planning support systems (PSSs)

Figure 1. National comparison of online government service utilization (Graafland \& Ettedgui, 2003)

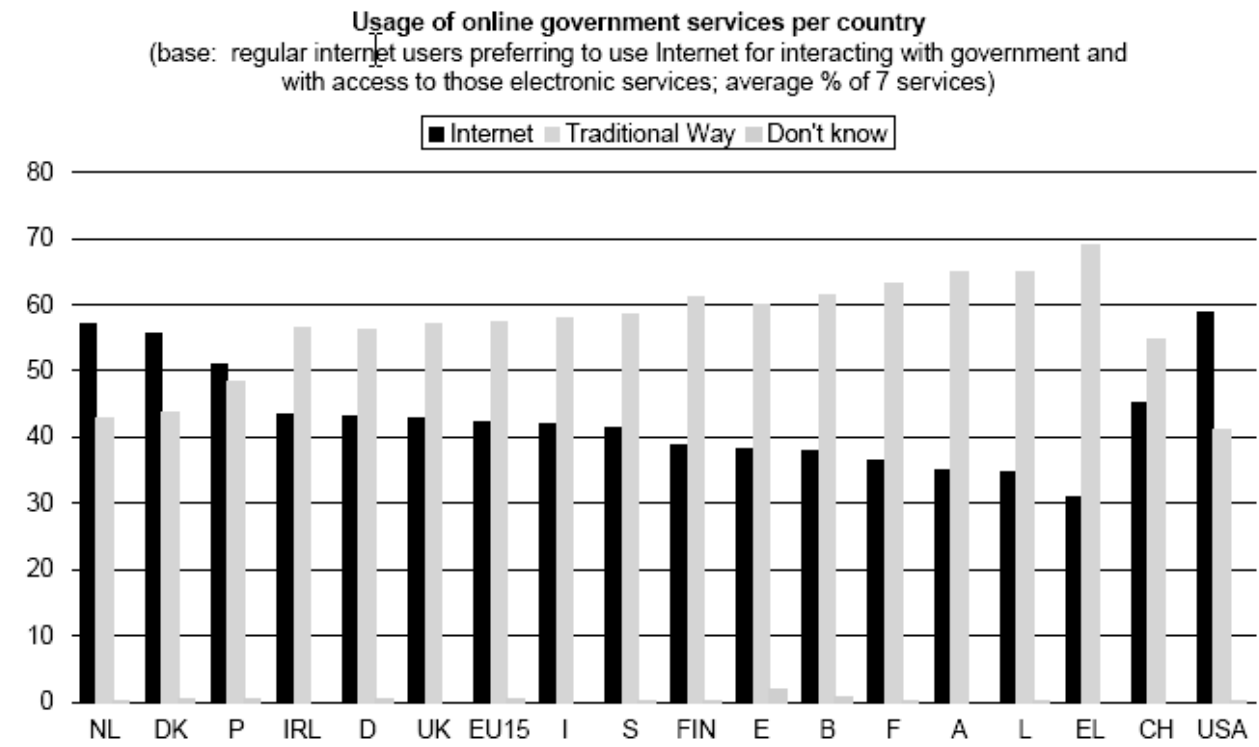


have increased the speed and quality of the urban planning process. PSSs do not have a very long history and are still quite a new topic in the urban planning profession (Brail, 2005). But there is no doubt the origin of PSS is based on the developments in decision support systems (DSSs). At present in literature the terms PSS and DSS are used in the same context.

DSSs have been implemented widely in various disciplines for many years. They were originally developed in academia for experimental purposes, but like many other technologies, they became one of the most innovative technologies in parallel to rapid developments in software engineering as well as developments and advances in hardware. Particularly, in the last decade the awareness of DSSs have been dramatically heightened with the increasing demand for a better, more reliable, and furthermore a transparent decision-making process (Klosterman, Siebert, Hoque, Kim, \& Parveen, 2003). The unique nature of planning requires that spatial dimension must be considered within the context of DSS. Additionally, the rapid changes in socio-economic structure in a dynamically changing complex urban environment cannot be easily monitored, controlled, or administrated without an effective DSS.

The complex interactions between power relationships and socio-economic dynamics in a large-scale urban environment require planning policies to be defined very carefully which in turn requires PSS. Those multi-dimensional relationships and interactions make implications of planning policies challenging because planning itself is not isolated from the societal structure. An efficiently designed PSS is vital for a successful plan implementation.

In this context, this chapter provides discussion on current developments in online participatory PSS, and investigates GIS-based PSS, GIS-based urban policy development, local governments' use of these technologies, and their importance for the planning process and KBUD.

\section{BACKGROUND}

The goals of KBUD can be achieved by using many system dynamic tools such as PSS, DSS, and GIS. These tools construct and enlarge our knowledge by providing a means of visualizing a large amount of information on planning and decision-making processes. Geertman (2001, p. 30) defines PSSs as:

...systems that have been developed and are being used to support current practice in any public or private sector planning context at any spatial scale. In fact, PSS is a term that refers to the diversity of geo-technology tools, which are primarily developed to support planning processes both in terms of derivation and evaluation of alternative [urban] futures.

PSSs are one of the most significant developments in urban planning technology. They have become a major research area in the field of planning starting in the early 1990s with the advancement in GIS. There have been ongoing efforts to integrate PSS models into GIS, and several GIS software products already have tools to facilitate PSS functionalities such as What-If, Index, and CommunityViz for ArcGIS. As mentioned above, most of this software is designed based on the idea that PSS - or in more general terms, DSS — can be integrated into existing GIS. Hence GIS might be utilized as a reliable PSS. Probably one of most successful examples is CommunityViz, which was developed by Orton Foundation as a GIS extension. CommunityViz can be considered a state-of-the-art PSS because of its scenario design component called Scenario 360. Scenario 360 allows users interactively to create and experiment in an urban environment with hypothetical scenarios. It can also be used for making and changing assumptions on the fly. Most importantly this scenario component's comprehensive and informed decision-making process could be used for empowering the public 
through information provision and participation (see Figure 2).

CommunityViz has a powerful visualization capability to create a photo-realistic 3D model of an existing urban setting or proposed plan; this feature also offers a profound communicative ground (see Figure 3). Consequently, users can compare alternative developments and policies in a visually enriched environment without the need of a technical background.

However, developments in PSS are still in the early phases and need to be developed to incorporate other related technologies, for example WebGIS services (Yigitcanlar, Baum, \& Stimson, 2003). Rapid developments on WebGIS are constantly changing the way people obtain, share, and use spatial information to be a part of decision-making processes (Peng \& Tsou, 2003). All these efforts bring up a quite challenging subject which requires radical changes in which the ways planning procedure is carried out. On the one hand, the organizational structure of a plan-making process should be redesigned to include people as stakeholders, and on the other, PSS should be flexible to include feedback from stakeholders (Geertman, 2002).

Furthermore, well-known time-space compression is another challenging topic in GIS-based PSS. Information stored in the geographic information database often represents reflection of the snapshot of the present. In other words, information in GIS gives us a snapshot of the real world. However, urban phenomena are rapidly changing, and any GIS- and GIS-based PSS should be able to handle this issue. GIS often lacks processing temporal information which leads to failure to track dynamic changes in a complex urban environment. Today, spatio-temporal GIS is one of the most important and challenging research areas since spatial behaviors are dynamic in nature, their attributes and locations are changing through time, and it is a quite complex task to model those behaviors. Although it is not a new issue, models with spatio-temporal GIS are still

Figure 2. CommunityViz Scenario 360 (Orton Foundation, 2007)

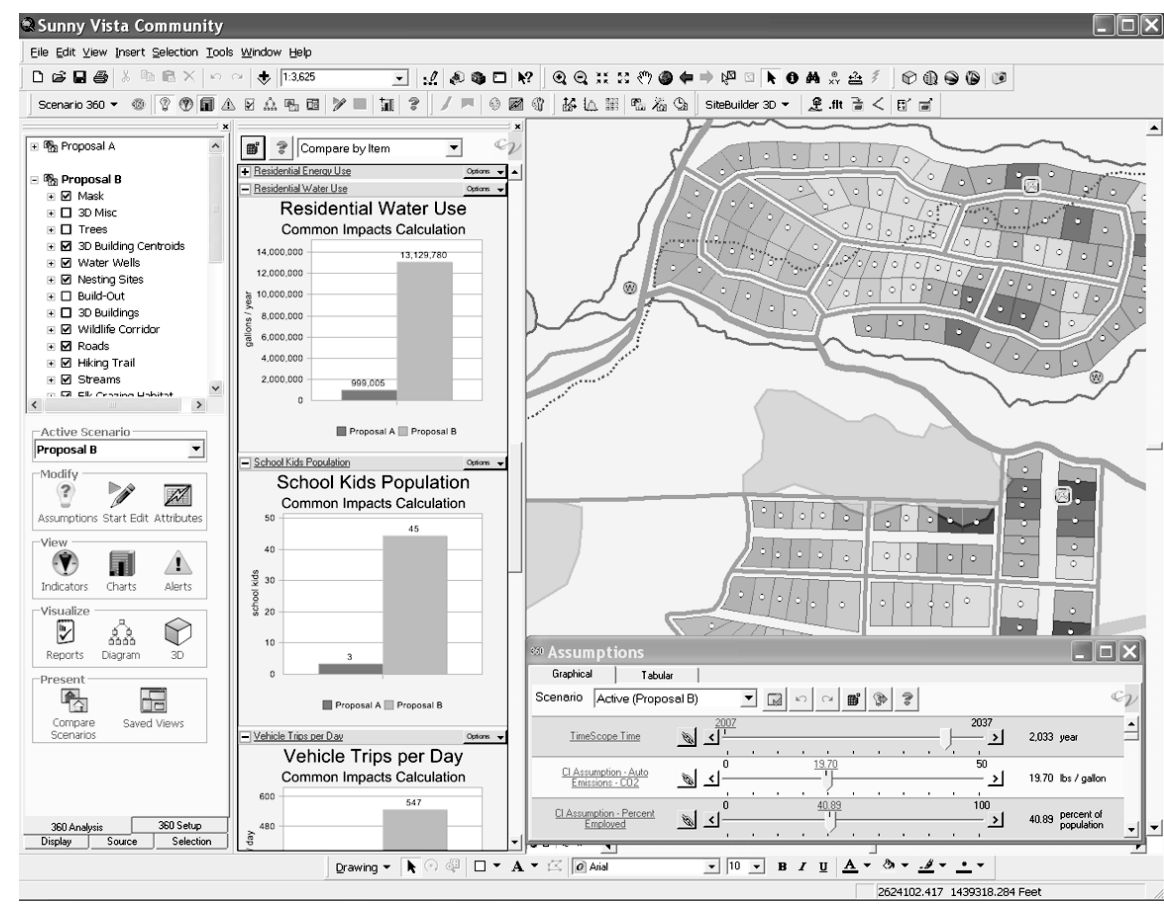


Figure 3. CommunityViz 3D visualization sample (Orton Foundation, 2007)

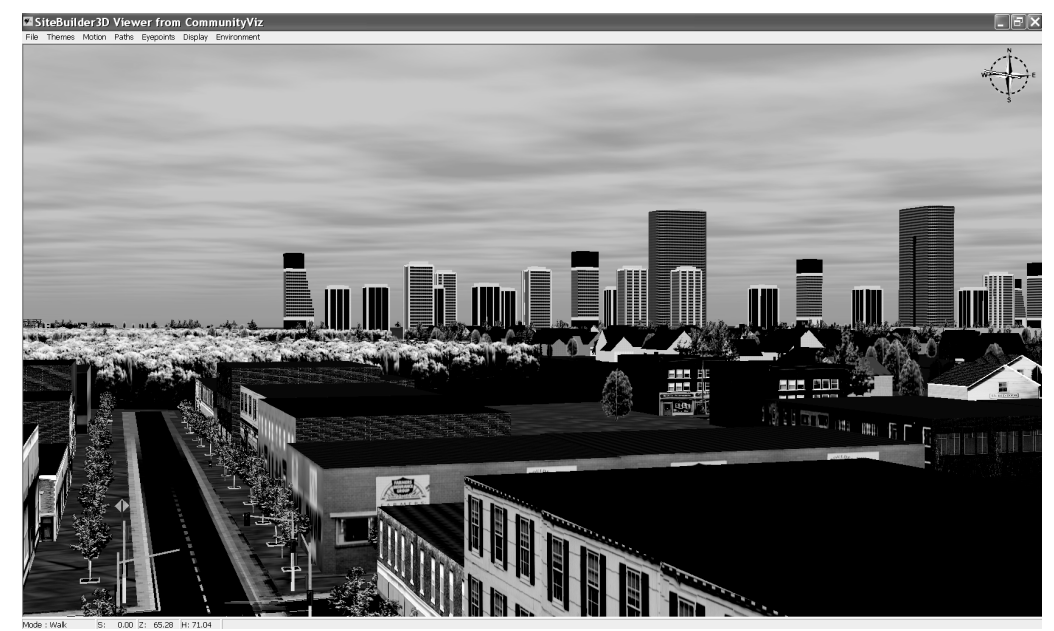

being developed. An example for these models would be the agent-based GIS, which considers individuals as independent objects and tries to model their behaviors using mathematical models and algorithms. Therefore, GIS plays an essential role in PSS, urban policy making, and also in KBUD.

\section{GIS-BASED PLANNING SUPPORT TOOLS}

The recent developments in GIS are creating an enormous opportunity for accessing up-to-date information which provides a significant foundation for the planning of KBUD. In general terms, GIS is basically a tool to collect, store, and analyze geographically referenced data or 'spatial data'. This broad definition refers to any geographic objects based on a common coordinate system. As for geographic information (GI), it defines the attributes of those geographic objects. However, GI is not a simple piece of information about the real-world phenomena. In other words, GI is a complex object more than solely an element in a geographic information database as a component of GIS.
In fact, PSS and GIS cannot be isolated from each other since both systems are mostly focusing on the geographical aspect of urban space. Hence, how these two systems are related to each other is an important issue. There are number of GIS applications which are referred to spatial decision support systems (SDSSs) and, there is no single definition.

However, disagreement on the definition of SDSS also arises from the separation of GIS research from other DSS-related research. To a large extent the term SDSS is used in the GIS research. To a large extent the term SDSS is used in the GIS research community with little reference to the DSS field generally...In a similar way the term SDSS may be used to describe DSS applications with a simple mapping component where little or no GIS technology is used. (Mora, Guseppi, \& Gupta, 2003, p. 30)

SDSS can also be defined as a GIS itself, and a DSS and GIS could be utilized to empower policymaking process. As it could be drawn from former discussions, it is not easy to distinguish DSS and SDSS from each other and there is still an ongoing debate on this issue. 
As discussed earlier in this chapter, PSS is quite a new topic particularly for urban and regional planning. A number of articles on PSS have been published, and it is also discussed in planning conferences. As a result of ambiguity on definition and functions of PSS, its application is quite problematical. In spite of all these obstacles, some vendors developed their off-theshelf products such as CommunityViz Scenario 360 Suite, What-If?, Index, and Urban Sim. According to Klosterman (2005), it would be more productive to identify different types of PSSs as shown in Table 1.

At present, PSSs have found a wide range of application areas ranging from environmental to neighborhood planning, accessibility to urban planning, and transportation to online participatory planning (Vonk, Geertman, \& Schot, 2005). Although PSSs are widely used, Geertman (2001, p. 13) points out serious obstacles that clearly need to be addressed.

At the moment, people at a diversity of scientific, research, and planning institutions worldwide are involved in the development, testing, and application of a whole range of PSSs. However, the full extent of the developments and implementation of PSSs are totally unknown. At the same time, the planning community has little idea of where to look for instruments, advice, and support for PSS, beyond the employment of expensive consultants. This is problematic for both the potential consumers and producers of PSSs - given that planners possess an increasing need for geotechnology support, but geotechnology vendors have to prove the worth of their products in real-world planning situations.

The applications of PSSs vary in a widespread perspective, and PSSs are used for different purposes. Geertman (2001) stated that there are different types of PSSs. The first group of PSSs focuses on routine tasks of planning process such as simulation, modeling, and analysis, while the second group of focuses on visualization, communication, and GI as a communication tool that could be used for participatory planning, which is critical for KBUD. Another PSS group serves as DSSs for policymakers to evaluate consequences of alternative planning scenarios. Finally the last group mainly focuses on monitoring urban phenomena and evaluating the performance of existing planning decisions so that policies can be revised quickly and very efficiently, and most of all this approach enables the feedback process (Geertman, 2001).

As can be concluded from above statements, the use of PSS mainly focuses on making plans as a part of the planning process. However, the planning process is more than making plans; it is also concerned with implementation of plans and is very complex in nature. It is often claimed

Table 1. Categorization of selected planning support systems (Klosterman, 2005, p. 478)

\begin{tabular}{|c|c|c|c|c|}
\hline TASK $\rightarrow$ & Land use/land & Comprehensive projec- & & \\
\hline TECHNIQUE $\downarrow$ & cover change & tion & 3D visualization & Impact assessment \\
\hline Large-scale urban & $\begin{array}{l}\text { Metropilus, } \\
\text { Spartacus, Tra- } \\
\text { nus, UrbanSim }\end{array}$ & $\begin{array}{l}\text { Metropilus, Spartacus, } \\
\text { Tranus, UrbanSim }\end{array}$ & & \\
\hline Rule-based & Cuf, What-If? 1.1 & What-If? 2.0 & CommunityViz & $\begin{array}{l}\text { CommunityViz, Index, } \\
\text { Place's }\end{array}$ \\
\hline State-change & Cuf II, Curba & & & \\
\hline Cellular automata & Sleuth, Duem & & & \\
\hline
\end{tabular}


that making plans follows certain steps, but this point of view is not realistic in practice since the planning process involves many tangible and intangible factors. Particularly, intangible factors have significant effects on both the resulting plan and its implementation. Because of this reason, "the activity of making plans is infrequent, dispersed, idiosyncratic and highly unstructured in practice" (Hopkins \& Varkki, 2005, p. 599).

The activity of using plans, on the other hand, is frequent and in many cases is carried out within the semi-structured deliberations of planning boards, community meetings, city council meetings, or court proceedings. From conventional arguments that computer-enhanced support systems are most likely to be valuable in repetitive, incompletely structured situations, PSSs are more likely to be successful if they support planners, legislators, and citizens when using plans in deliberative decision making rather than, or at least in addition to, when making plans (Hopkins \& Varkki, 2005, p. 599).

As can be seen, actually each group of PSSs represents its different roles in different levels and steps of the planning process. The key to a successful plan implementation is that the PSS should also be able to support a communicative planning approach (Snyder, 2001). At this point the PSS can be considered as a mediator between policymakers, planners, and the public. If PSSs play a role in communicative planning - in other words, collaborative planning - the only solution seems to be the integration of it into WebGIS - as an online participatory PSS. The idea of WebGIS is an attempt to discover the ways people/stakeholders actively participate in the spatial decisionmaking process, and consequently this approach refers to participatory GIS or public participation GIS (PPGIS) (Yigitcanlar, 2002).

A number of benefits can be achieved in the planning process by utilizing WebGIS for public participation. These include: improvement of the decision process, increased confidence of the public in the given information, increased influence of the general public opinion, increased number of active participants, increased involvement, and expression of opinions of the general public in the process (Gudes, Stern, \& Savoray, 2004).

There are a number of advantages of WebGIS over traditional GIS since users are able to get vast information through the World Wide Web, and also perform some basic and major GIS functions

Figure 4. A sample Mapquest query (www.mapquest.com)

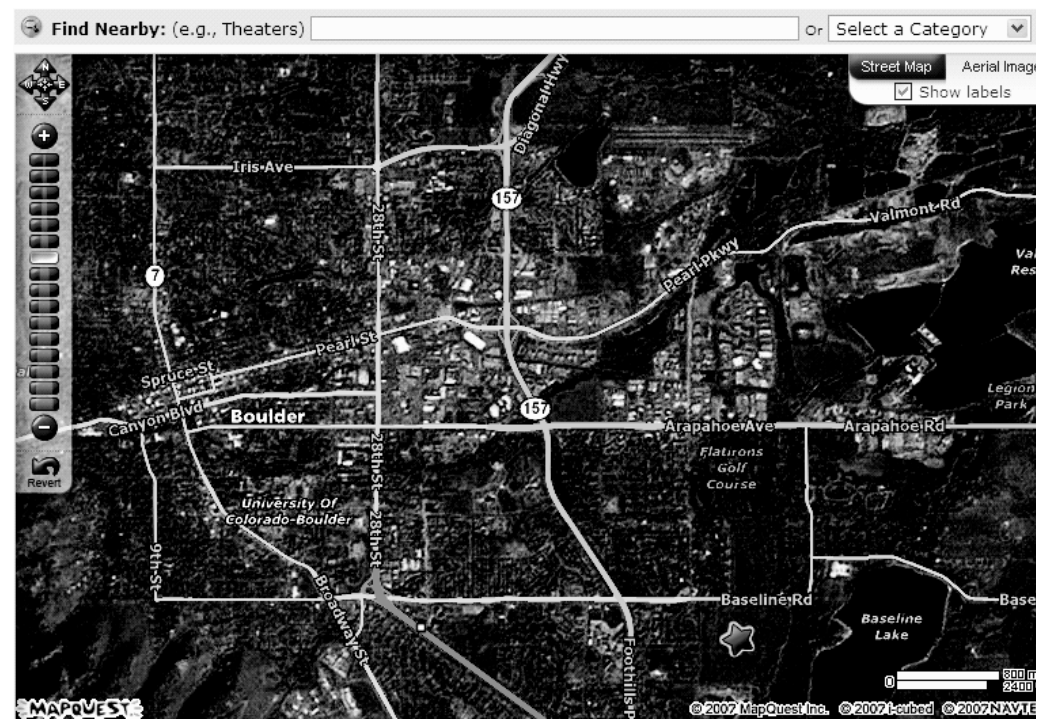


like spatial queries. Perhaps the most common examples of spatial queries are address locating services such as Mapquest (www.mapquest.com) and GPS-based navigation systems which are rapidly spreading.

On the other hand, at the more advanced level users can create their own maps using either server-side GIS or client-side GIS techniques. For example, Geography Network (www.geographynetwork.com), developed by ESRI, is a client-side GIS which enable users to access a number of spatial data sources on the Internet so users can query spatial data in real time and create their own maps very easily.

At the moment, the field of WebGIS services are developing rapidly and allowing users to access the basic functions of remote sensing technology (i.e., aerial photos and satellite images). Google Earth (earth.google.com) is a very successful service developed by Google Inc. which is a client-side GIS application. Another successful example is the Microsoft Virtual Earth project (www.microsoft.com/virtualearth).

WebGIS has several advantages compared to traditional GIS as mentioned previously. These advantages are briefly summarized below to emphasize the power of WebGIS and GIS-based PSS (Craig, 2003, p. 9):

- Unlike traditional GIS, users are not required to purchase and install GIS software. Users also do not have to upgrade their software, since they are provided with centralized WebGIS services. This issue is particularly important as this way, less-privileged users are empowered to use capabilities of GIS.

- $\quad$ All users are using the same PSS tools and WebGIS since applications are distributed through the Internet and this reduces maintenance and distribution costs. Like applications, spatial data are stored in a central database; this ensures that data distribution is unified, and moreover users do not have to download large datasets in their personal computers.

- $\quad$ Although hardware prices are decreasing while computing power of personal computers is increasing, processing a high volume of spatial data requires powerful servers and spatial analysis can be performed just through Web browsers.

Figure 5. A Google Earth sample location query (earth.google.com)

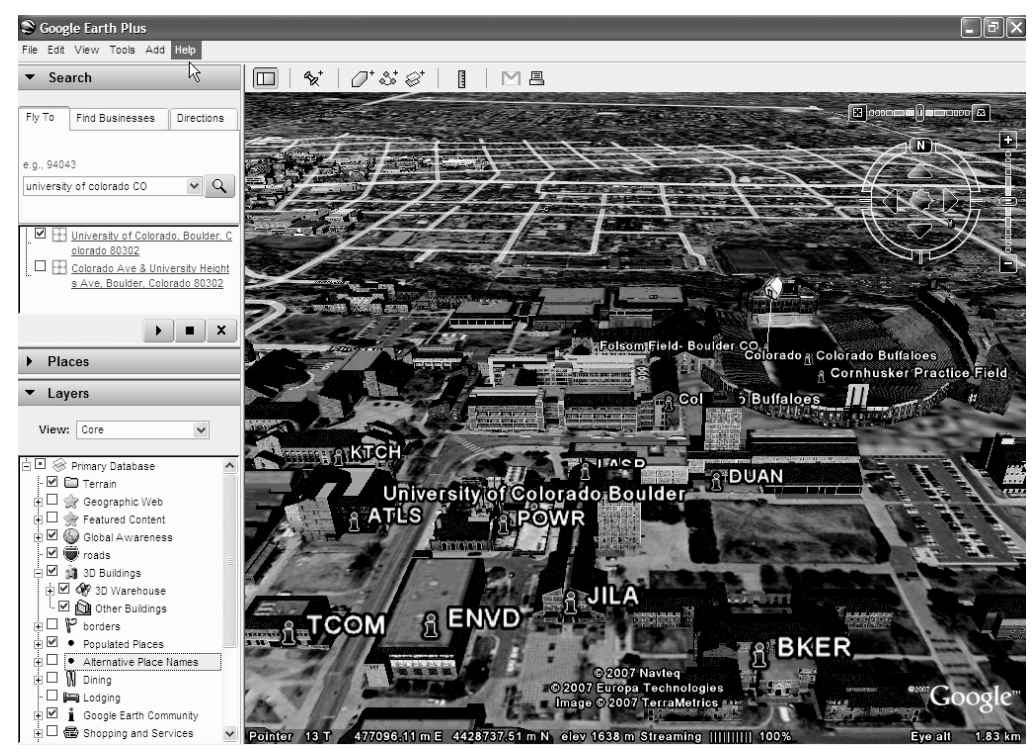


Despite all those great advantages of WebGIS and Web-based PSS, there are some serious obstacles that must be resolved. First of all, not everyone has Internet access, especially low-income groups, minorities, and users in less-developed countries. Hence, it is doubtful whether the public can really take part in the decision-making process. The key point here is which public constitutes the public in participation. Considering the fact that the public consists of individuals, ideally each individual should be able to participate. "A person must translate his freedom into an external sphere in order to exist as idea" (Hegel in the 1821 Philosophy of Right, in Curry, 1998, p. 88). "On this view an individual becomes an individual only through interactions with others, through existence within a community" (Curry, 1998, p. 89) — in other words, who are entitled to access and can participate in the decision making is critical.

As discussed earlier, users play a role in the decision-making process through their Web browsers with a simple Internet connection. What users see is a model of the real world, and of course all models are structured on an ideology. In other words, the space in which users can interact with PSS is abstract. This is why GIS is criticized by post-positivists. As mentioned earlier, "Today GIS is heavily criticized because of positivist assumptions ignoring societal (irrational) realities" (Saygin, 2002, p. 60). According to Soja (1989), a generalized and physically abstract space concept neglects socially constructed space that is needed to understand social and spatial dialectics. On the contrary, this physical space approach does not have an epistemological ground to analyze subjective and observable characteristics of spatiality of society.

It is generally accepted that the space in GIS is the model of the real world. This also raises another assumption that the information in a spatial database is objective, neutral, and not distorted by any means. WebGIS is partly based on this assumption because information is distributed from a central database and all users are using the same uniform datasets. It should also be kept in mind that "all data are selections from reality, based on the world view or theoretical models of the era, as filtered through the standpoints of particular groups in each era" (Wallerstein, 1996, p. 91). The objectivity of spatial data is questionable like what constitutes the public. The subjectivity of data collection based on a certain viewpoint cannot be denied. This brings another issue into the agenda which is: Whose objectivity? Posing this question is very important since political, economic, and social motivations transform all levels from the designing of GIS software to the data collection and classifying (Stuart, 1995).

Of course, these issues and discussions are not limited to WebGIS or GIS. In general, information technologies would always be posed such criticisms from the view of different ideologies. Despite all criticisms, WebGIS offers a very effective medium for PSS, and online participatory PSS will continue to develop and become widely available as the awareness on these technologies increases.

\section{GIS-Based Urban Policy Development}

The last two decades have witnessed a rapid growth in global economy and the trend led by technical, organizational, and financial changes on a global scale. Consequences of the rise of ICT removed boundaries between nations, made vast information sources available through the information highway, and inevitably and dramatically changed both production and consumption. These unforeseen changes also brought a dilemma into the agenda which today many critics called the digital divide (Alaedini \& Marcotullio, 2002).

Consequently, this unavoidable rise of ICT has both positive and negative effects from a local to a global scale. More urbanized parts of a nation could access and use ICT more effectively in a productive way, while rural or less developed parts 
are somehow isolated from ICT. This disparity will continue to grow unless a balanced information infrastructure policy is developed, and this makes national information infrastructure critically important to developing and less developed countries (Saygin, 2002). Developed countries face the same dilemma to some extent. Inequalities between nations and within the nations in terms of using ICT cause many more serious problems than underdevelopment/development discourse.

As for the GIS and GI technologies, the situation is somewhat different and even worse since GIS technology is at the intersection of several factors such as institutions, human factor, finance, political power relationship, and so on. The relationships between those factors are highly interactive, and in most cases some of them are contradictory to each other (Saygin, 2002).

Most of the developing countries see GIS just as an automated mapping system. In parallel to this type of thinking, there is a lack of communication and coordination, and no common language among those agencies involved in planning and managing a GIS project. Almost every agency uses a different data format, different software, and a different database structure that is often incompatible with another. Given the conditions of developing countries, this is not a totally unexpected result where personal conflicts, power relationships, political debates, and almost constantly changing investment priorities are together like a melting pot.

As opposed to a developing country context, in developed countries GIS has been heavily utilized for urban policy development. Most policymakers are well aware of the potential of GIS, as GIS-based indicators provide valuable information, particularly if they are policy related and to some extent they are able to generate better decisions and evaluate the policy performance. For example, GIS-based indicators can be valuable tools to describe differences in the quality of life and access to services and identify trends (Martinez, 2004).
GIS has a positive impact on urban and local decision making, as it eliminates data redundancy and facilitates a systemic approach to problem solving. GIS ensures accuracy of the data and presents information in a user-friendly format, though frequently, a problem can be better understood if visualized on a map. Visualization assists exploration, and in this respect GIS supports local planners who can test any idea and policy by alternately tightening and relaxing conditions and assumptions (Brudney \& Brown, 1992).

Many factors can be included in analysis (soils, property ownership, land values, topography) to compare alternative sites or routes for new infrastructure. The same can be analyzed by a local council committee that makes a preliminary choice and recommends it to the whole council. In this respect, visualization supports communication from policy group to decision-making body. After the finaldecision is made, it is communicated to the public. Gaining public support for a new project can also be supported by GIS-generated expertise. The most direct effect is observable in the maintenance of land records and delivering related services.

Through it is easy access to data, GIS applications can stimulate improvements in the performance of local government tasks: land-use and urban growth planning, economic development, infrastructure and transportation management, and healthcare. To fully perform these tasks, the development of appropriate organizational structures and processes in local governments is the foremost issue. In this sense, the concept of an 'urban information system' (UIS) began to be popular in local governments. UIS is used as an umbrella term encapsulating all of the efforts in an information system — geographic, management, or land information systems - or information technologies such as the Internet. UIS and the Internet generally are used together to perform local government operations (Velibeyoglu, 2005). UIS, therefore, can be considered as an effective tool for local governments in order to manage all 
physical, social, cultural, and economic activities, and it offers a well-qualified service environment, which is also required for KBUD.

By combining many of the local government services into an UIS, service unity, a reduction in service costs, and an increase in revenues could be obtained (Heeks, 1999). Since information technologies and systems generally incorporate a significant set of rational structures, processes, cultures, professional strategies, and involvement, they bring basic changes in the processes and management of organizational environments. In order to employ information systems like GISs for better decision support and performing local government tasks efficiently, organizations need to complete pre-requisite conditions and pay considerable attention to the careful management of the utilization process.

\section{Local Governments and the Use of GIS}

At present a majority of local governments are benefiting from the use of GIS applications and mapping technology. A 2003 survey in the United States (Sarkar, 2003) shows that about $97 \%$ of local governments with populations of at least 100,000 , and $88 \%$ of those between 50,000 and 100,000 people, use GIS technology, according to Public Technology Inc., a nonprofitresearch group that conducted the study in collaboration with several national municipal associations. In addition, $56 \%$ of smaller governments - jurisdictions with fewer than 50,000 people — also utilize such applications. The report pointed out that county use is slightly higher than city use, $72 \%$ vs. $64 \%$. Sponsored by the Interior Department, the survey of 1,156 local governments is part of a collaborative effort to develop the Geospatial One-Stop system, a federal project to help facilitate the collection and sharing of geographic or spatial data among federal, state, and local governments. The report indicated that GIS applications have become integral resources in various local functions, including urban planning, public works, financial, public safety, and economic development.

Similarly another survey conducted in Australia in the same year (Yigitcanlar, 2005b, 2006) indicates that GIS applications are firmly embedded in most of the local planning authorities (89\%). The growth of the Internet made it possible to obtain a wide range of services online. The use of the Internet and GIS is a recent development in the provision of planning services to the public. Many planning authorities have responded to the challenge by providing a range of sites orientated toward various aspects of service delivery. In most of the Australian local councils, technical applications such as GIS and the Internet are now becoming well established, though some of them are still being developed and enhanced.

Most city, town, and shire administrators appear concerned about providing online services to citizens to encourage their participation in the planning process. A significant number of them are planning to provide information and planning services online. Currently $49.3 \%$ of responding councils intend to use the Internet as a tool for public participation-at different levels-for planning. When the metropolitan and regional divide in councils' intention to utilize ICTs was analyzed, it was observed that in general metropolitan councils have greater intent to use ICTs as a public participation medium compared to regional councils. Additionally large (city) councils are more willing to apply ICTs for online planning than smaller (town and shire) councils. Most city, town, and shire administrators are extremely interested in providing online planning, including online transactions to their residents. A high majority $(86.4 \%)$ of the councils are interested in using the Internet for online planning within the next five years. Besides these findings, Yigitcanlar (2005b) reveals the results of a more recent analysis that GIS is now becoming an integral part of urban policymaking in major Australian cities. Additionally, PSSs have already become important supporting tools for KBUD in major capital cities (i.e., Sydney, Melbourne, and Brisbane). 


\section{CONCLUSION}

KBUD is an ideal new medium in which to grow more livable, stimulating, cleaner, intelligent, enlightened, tolerant, and meaningful communities/cities worldwide (Yigitcanlar, 2007). A PSS can undoubtedly be a powerful tool for KBUD, urban planning, and policymaking by supporting local knowledge networking, not only within the economic sphere, but within social, cultural, and civic dimensions of the city as well.

Since the advent of modern urban and regional planning, planners have traditionally relied heavily on maps and various kinds of data to assist in the decision-making process. The KBUD process can be supported with an online system as a means of obtaining and sharing information/knowledge where much of the process is partially or fully automated. In the last three decades, a mechanism for prediction or modeling has been made available to collaborative processes through the use of computer-based analysis tools, and most recently PSS. The advances in computer technology have also made the practical integration of spatial (map-based) and non-spatial information possible (demographics, ownership, land values, economic, environmental, etc.). Linking maps to relevant data via these new PSSs becomes a relatively new tool of urban planners.

Public participation has long been recognized as an important component of the planning process. PSS offers a flexible opportunity to enhance participatory planning activities. The use of online participatory PSSs to support the planning process is becoming more common in many communities all around the world. As a result, planning discipline - and practice-is becoming more transparent and democratized.

Especially the growth in the WebGIS field has been phenomenal, particularly during the last decade, and the number of WebGIS and related applications is rapidly increasing (Yigitcanlar, 2006). There is also no doubt that WebGIS makes online participatory PSS development possible.
One of the major advantages of using WebGISbased PSS is that the public can actively participate in decision-making and planning processes, and this would lead to the creation of an interactive and democratic planning environment, which is a requirement for achieving KBUD. But at this point there are limitations that also need to be taken into account. Two aspects of PSS should never be ignored. The first one relates to problem-oriented tools. The second is that PSSs are not bias-free because the philosophy behind their design always reflects the cultural, economic, and political settings in which they are developed. Subsequently, it may not be quite realistic to argue that a WebGIS-based PSS would necessarily make the decision-making process more democratic and transparent. Additionally, a PSS-either WebGIS based or stand-alone-would never become a standardized, universal tool because its structure and the assumptions behind its design would always be based on political and social settings and conditions. Another related issue is the property of spatial data. The question that needs to be answered here is: Who owns spatial data? The answer is not simple; it is actually quite complex since the information flow is controlled by political formation. There is also a possibility of manipulating information to serve certain interest groups and stakeholders. Therefore, a WebGIS-based PSS could be an anti-political or political machine, but could not be fully neutral and/or bias-free.

At present WebGIS is only able to provide a few sets of GIS functions because of current technical limitations. Client-side WebGIS applications offer a more flexible environment for users compares to server-side WebGIS applications. Since, the true WebGIS on the Web requires more sophisticated GIS functions and spatial analytical functions, next-generation WebGIS applications need to comprise complicated, related technologies such as remote sensing and global positioning systems, $3 \mathrm{D}$, and real-time models. Current trends in the GIS industry point out a promising view on 
the development of advanced methods to make WebGIS and PSS more efficient. The rapid developments in technology and particularly online participatory PSS will likely continue to increase, and in the near future users will be able to benefit more from these technologies. It will also assist communities and urban administrators solving $21^{\text {st }}$ century cities' major problems: increasing inequality and insecurity, social defragmentation, isolation and exclusion, and thoughtless damaging of the environment.

Lastly, we conclude with a quote from Pamuk's (2006, pp. 1-2) book, Mapping Global Cities: GIS Methods in Urban Analysis:

Spatial thinking and analysis are essential for intelligent urban policymaking in a globally connected world. Urban planners and policymakers need to understand how cities are organized and how residential patterns are shaped as a result of population and employment changes. Otherwise, they risk designing urban plans and policies that are unrealistic and exclusionary. [Online participatory PSS] can be usefully applied by planners to new urban development challenges in global metropolitan regions and mega cities [for KBUD], particularly those where rapid demographic changes, including immigration, have spurred massive growth. The analysis of relevant data with GIS can provide a powerful new perspective in addressing urban research and policy questions, and holds the potential to deepen our collective understanding and efforts in solving important urban policy problems.

\section{FUTURE RESEARCH DIRECTIONS}

The implications of the GIS technology for the urban planning discipline are enormous. All around the world planners and policymakers are getting accustomed to using GIS for urban planning and policymaking. New data sources emerging in real time and software to understand many elements of the working of cities such as simulation games and GIS are now widespread (Batty, 1995). Also, this situation points out the importance of and provides an opportunity for the use of information technologies and particularly GIS tools in urban planning and policymaking.

Changes in the technology, especially advances in object-oriented programming systems and widespread digital connectivity via the World Wide Web, are fundamentally redefining and restructuring the way planners will interact with computers, and with the data and models stored on those computers. The specification of spatial objects, spatial-data libraries, object-oriented programming, and programming languages such as Java seems to be quite suitable to develop applications which can be accessed using an Internet browser. Java-based applications are being widely used by leading software companies, such as Mapextreme by MapInfo and ArcGIS Server Enterprise Standard by ESRI, to let users query remote geographic databases and create their very own maps with just a few clicks. Similarly Autodesk MapGuide Enterprise and Open Source MapGuide products are among the important software solutions for WebGIS.

These trends point to a future when the next paradigm for GIS will be PSSs with embedded spatial support systems with embedded spatial data and process models, enabling stakeholders to take part in the planning (Heikkila, 1998).

According to Heikkila (1998, p. 358), the future of GIS in planning and the ways that planners will use and conceive of GIS will be interrelated to the following six propositions:

1. The core of the computing universe will continue to shift dramatically from the desktop or stand-alone CPU to the network, and planners will not be exempt from this pervasive trend.

2. Spatial models - both spatial data models and the spatial process models that interact with them-will be integral components of emerging PSSs. 
3. Emerging standards for spatial model protocols will facilitate the integration of PSS model components that are derived from disparate sources and that were developed for distinct purposes on diverse platforms, and planners will look more to the Internet network to supply ingredients for their PSSs.

4. Increasingly sophisticated user interfaces will enable planners to focus more on the 'what' and 'why' rather than on the 'how' of GIS models.

5. The communicative and collaborative aspects of planning will be strengthened, as PSS model building becomes more of a shared enterprise among diverse stakeholder groups.

6. Dispersed, network, and communication-based planning support systems with embedded spatial objects will be the new paradigm for planning GIS.

In the course of time, there is a trend and transition from a 'personal GIS' in which single users access their own data on their own machines, to 'departmental GIS' in which multiple users working for a single department (e.g., a local government planning department) can access a departmental database, to 'corporate GIS' in which people working in several departments across a corporate entity (such as the local government) can access a centrally maintained and shared corporate database, and finally to 'societal or WebGIS' with many people accessing many databases located all over the world. Thus, in the near future more GIS-based urban planning and policymaking projects/practices will likely go online on the Web.

\section{REFERENCES}

Alaedini, P., \& Marcotullio, P. (2002). Urban implications of information technology: New electronics for developing countries. Journal of Urban Technology, 9(3), 89-108.

Batty, M. (1995). The computable city. In Proceedings of the $4^{\text {th }}$ International Conference on Computers in Urban Planning and Urban Management, Melbourne, Australia.

Brail, R. (2005). Planning support systems evolving: When the rubber hits the road. In J. Portugali (Ed.), Complex artificial environments. New York: Springer.

Brudney, J., \& Brown. M. (1992). Do geographic information systems meet public managers' expectations? State and Local Government Review, (Spring), 84-90.

Craig, W., \& Dunn, C. (2003). GIS in participatory research: Assessing the impact of landmines on communities in North-West Cambodia. Transactions in GIS, 7(3), 393-410.

Curry, M. (1998). Digital places: Living with geographic information technologies. New York: Routledge.

Essers, I., \& Ettedgui, E. (2003). The final report of the project funded by the European Community under the "Information Society Technology" program (1998-2002). Retrieved May 8, 2007, from http://www.rand.org/pubs/monograph_reports/MR1733

Geertman, S. (2001). Planning supportby PSS: An inventory. Proceedings of the $37^{\text {th }}$ International ISoCaRP Congress-Planning in the Information Age.

Geertman, S. (2002). Participatory planning and GIS: A PSS to bridge the gap. Environment and Planning B: Planning and Design, 29, 21-35.

Gudes, O., Stern, E., \& Savoray, T. (2004). Geographical information systems on the Web for public participation in planning. In Proceedings of the $12^{\text {th }}$ Conference on Geoinformatics - G eospatial Information Research: Bridging the 
Pacific and Atlantic (pp. 459-463), University of Gavele, Sweden,

Heeks, R. (1999). Better information age reform: Reducing the risk of information systems failure. In R. Heeks (Ed.), Reinventing government in the information age. London: Routledge.

Heikkila, E. (1998). GIS is dead; long live GIS. APA Journal, 64(3), 350-360.

Hopkins, N., \& Varkki, G. (2005). Representing urban development plans and regulations as data: A planning data model. Environment and Planning B: Planning and Design, 32(4), 523-545.

Klosterman, R. (2005). An update on planning support systems. Environment and Planning B: Planning and Design, 32, 477-484.

Klosterman, R., Siebert, L., Hoque, M., Kim, J., \& Parveen, A. (2003). Using an operational planning support system to evaluate farmland preservation policies. In S. Geertman \& J. Stillwell (Eds.), Planning support systems in practice (pp. 391-407). Heidelberg: Springer-Verlag.

Martinez, J. (2004, May 10-12). The integration of GIS into policy making through intra-urban indicators. Proceedings of the GISDECO 7th International Seminar on GIS in Developing Countries, Universiti Teknologi Malaysia.

Mora, M., Guseppi, A., \& Gupta, J. (2003). Decision making support systems: Achievements, trends, and challenges for the new decade. Hershey, PA: Idea Group.

Orton Foundation. (2007). CommunityViz product overview. Retrieved May 8, 2007, from http:// www.placeways.com/pdf/brochures/OverviewPDF.pdf

Pamuk, A. (2006). Mapping global cities: GIS methods in urban analysis. New York: ESRI Press.

Peng, Z., \& Tsou, M. (2003). Internet GIS: Distributed geographic information services for the internet and wireless networks. Hoboken, NJ: John Wiley \& Sons.

Sarkar, D. (2003). Local governments use GIS. Retrieved July 15, 2006, from http://www.fcw. com/article 85886

Saygin, O. (2002). GIS based urban policy development. Unpublished PhD Thesis, Dokuz Eylul University, Turkey.

Shiode, N. (2000). Urban planning, information technology, and cyberspace. Journal of Urban Technology, 7(2), 105-126.

Snyder, K. (2001). Tools for community design and decision-making. In S. Geertman \& J. Stillwell (Eds.), Planning support systems in practice (pp. 99-120). Heidelberg: Springer-Verlag.

Stuart, A. (1995). Who contrives the "real" in GIS? Geographic information, planning and critical theory. Cartography and Geographic Information Systems, 22(1), 17-29.

Velibeyoglu, K. (2005). Urban information systems in Turkish local governments. In Marshall, S., Taylor, W., \& Yu, X. H. (Eds.), Encyclopedia of developing regional communities with information and communication technology. Hershey, PA: Idea Group Reference.

Vonk, G., Geertman, S., \& Schot, P, (2005). Bottlenecks blocking widespread usage of planning support systems. Environment and Planning A, 37, 909-924.

Wallerstein, I. (1996). Open the social sciences: Report of the Gulbenkian Commission on the restructuring of the social sciences. Stanford, CA: Stanford University Press.

Yigitcanlar, T. (2001). GIS based participatory decision making approach. Unpublished $\mathrm{PhD}$ Thesis, Izmir Institute of Technology, Turkey.

Yigitcanlar, T., (2002, April 3-5). Community based Internet GIS: A public oriented interactive decision support system. In S. Wise, H. Y. Kim, 
\& S. Openshaw (Eds.), Proceedings of GISRUK: GIS Research UK $10^{\text {th }}$ Annual Conference (pp. 63-67), University of Sheffield, UK.

Yigitcanlar, T. (2005a, November 28-30). The making of knowledge cities: Lessons learned from Melbourne. In Proceedings of the International Symposium on Knowledge Cities. Medina: World Bank and Arab Urban Development Institute.

Yigitcanlar, T. (2005b). Is Australia ready to move planning to an online mode? Australian Planner, $42(2), 42-51$.

Yigitcanlar, T. (2006). Australian local governments' practice and prospects with online planning. Urban and Regional Information Systems Association, 18(1), 7-18.

Yigitcanlar, T. (2007). The making of urban spaces for the knowledge economy: Global practices. In A. Al-Furaih, A. Sahab, A. Hayajneh, A. Abdullah, M. Ibrahim, \& M. Thalha (Eds.), Knowledge cities: Future of cities in the knowledge economy (pp. 73-97). Malaysia: Scholar Press.

Yigitcanlar, T., Baum, S., \& Stimson, R. (2003). Analysing the patterns of ICT utilization for online public participatory planning in Queensland, Australia. Assessment Journal, 10(2), 5-21.

\section{ADDITIONAL READING}

Bernard, L., \& Kruger, T. (2000). Integration of GIS and spatio-temporal simulation models: Interoperable components for different simulation strategies. Transactions in GIS, 4(3), 197.

Borne, P., Fayech, B., \& Hammadi, S. (2003). Decision support system for urban transportation networks. IEEE Transactions on Systems, Man and Cybernetics: Part C-Applications and Reviews, 33(1), 67.

Carswell, J., \& Tezuka, T. (2006, December 4$5)$. Web and wireless geographical information systems. Proceedings of the 6th International Symposium (W2GIS 2006), Hong Kong. Retrieved from http://www.springerlink.com/content/9783-540-49466-9

Geertman, S., \& Stillwell, J. (2003). Planning support systems in practice. Berlin/New York: Springer-Verlag.

Heo, J., Kim, J., \& Kang, S. (2006). Temporal land information system (TLIS) for dynamically changing cadastral data. In Proceedings of Computational Science and Its Applications - ICCSA 2006 (pt. 2, pp. 1066-1073).

Jankowski, N., \& Prehn, O. (2002). Community media in the information age: Perspectives and prospects. Cresskill, NJ: Hampton Press.

Jensen, R.R., Gatrell, J.D., \& McLean, D.D. (2005). Geo-spatial technologies in urban environments. Berlin/New York: Springer-Verlag.

Kearns, F.R., Kelly, M., \& Tuxen, K.A. (2003). Everything happens somewhere: Using WebGIS as a tool for sustainable natural resource management. Frontiers in Ecology and the Environment, 1(10), 541-548.

Li, Z. (2007). Algorithmic foundation of multiscale spatial representation. Boca Raton, FL: CRC Press.

Luo, Y., Wang, X., Wang, W., Xu, Z., \& Ding, L. (2005). A hierarchical component-based WebGIS and its key technologies. Computing and Informatics, 24(3), 281-296.

Luo, Y., Wang, X., Xiong, G., \& Xu, Z. (2005). Design hierarchical component-based WebGIS. In Proceedings of Computational Science-ICCS 2005 (pt. 3, pp. 515-522).

Luo, Y., Wang, X., \& Xu, Z. (2004). Componentbased WebGIS and its spatial cache framework. In Proceedings of Advances in Web-Age Information Management (pp. 186-196). 
Mancarella, P., Raffaeta, A., Renso, C., \& Turini, F. (2004). Integrating knowledge representation and reasoning in geographical information systems. International Journal of Geographical Information Science, 18(4), 417-446.

Matejicek, L., Engst, P., \& Janour, Z. (2006). A GIS-based approach to spatio-temporal analysis of environmental pollution in urban areas: A case study of Prague's environment extended by LIDAR data. Ecological Modelling, 199(3), 261.

Matthew, Y., Cheung, P.S., \& Wenzhong, S. (2002). Development of a process-based model for dynamic interaction in spatio-temporal GIS. GeoInformatica, 6(4), 323.

Mayer-Schönberger, V., \& Lazer, D. (2007). Governance and information technology: From electronic government to information government. Cambridge, MA: MIT Press.

Mossberger, K., Tolbert, C., \& McNeal, R. (2007). Digital citizenship: The Internet, society, and participation. Cambridge, MA: MIT Press.

National Research Council (U.S.). Committee on Support for Thinking Spatially: The Incorporation of Geographic Information Science Across the K-12 Curriculum., National Research Council (U.S.). Board on Earth Sciences and Resources. Geographical Sciences Committee, and National Research Council (U.S.). Division on Earth and Life Studies. (2006). Learning to think spatially. Retrieved from http://fermat.nap. edu/openbook/0309092086/html/index.html

Oates, S., Owen, D., \& Gibson, R. (2006). The Internet and politics: Citizens, voters and activists. London/New York: Routledge.

Ott, T., \& Swiaczny, F. (1998). The analysis of cultural landscape change: A GIS approach for handling spatio-temporal data. History and Computing, 10(1/2/3), 37 .
Parent, C., Spaccapietra, S., \& Zimanyi, E. (2006). The MurMur project: Modeling and querying multi-representation spatio-temporal databases. Information Systems, 31(8), 733-769.

Sample, D.J., Heaney, J.P., Wright, L.T., \& Koustas, R. (2001). Geographic information systems, decision support systems, and urban storm-water management. Journal of Water Resources Planning and Management, 127(3), 155.

Stevens, D., Dragicevic, S., \& Rothley, K. (2007). iCity: A GIS-CA modelling tool for urban planning and decision making. Environmental Modelling and Software, 22(6), 761-773.

Tian, G., Liu, J., Xie, Y., Yang, Z., Zhuang, D., \& Niu, Z. (2005). Analysis of spatio-temporal dynamic pattern and driving forces of urban land in China in 1990s using TM images and GIS. Cities, 22(6), 400.

Van de Weghe, N. (2002). Development of a conceptual data model for digital spatio-temporal geographical information, with application to several themes and GIS. In Proceedings of Conceptual Modeling-ER 2002 (pp. 16-22).

Vatsavai, R.R., Shekhar, S., Burk, T.E., \& Lime, S. (2006). UMN-MapServer: A high-performance, interoperable, and open source Web mapping and geo-spatial analysis system. Proceedings of Geographic Information Science (pp. 400-417).

Wu, Y., Miller, H., \& Hung, M. (2001). A GISbased decision support system for analysis of route choice in congested urban road networks. Journal of Geographical Systems, 3(1), 3.

Yang, C., Wong, D., Yang, R., Kafatos, M., \& Li, Q. (2005). Performance-improving techniques in Web-based GIS. International Journal of Geographical Information Science, 19(3), 319-342. 